\title{
Assessment of cross-protection induced by a bluetongue virus (BTV) serotype 8 vaccine towards other BTV serotypes in experimental conditions
} (a) CrossMark

\author{
Ludovic Martinelle ${ }^{1}$, Fabiana Dal Pozzo ${ }^{1}$, Christine Thys ${ }^{1}$, Ilse De Leeuw ${ }^{2}$, Willem Van Campe ${ }^{3}$, Kris De Clercq ${ }^{2}$, \\ Etienne Thiry ${ }^{4}$ and Claude Saegerman ${ }^{1 *}$ (1)
}

\begin{abstract}
Bluetongue disease is caused by bluetongue virus (BTV) and BTV serotype 8 (BTV8) caused great economic damage in Europe during the last decade. From 1998 to 2007, in addition to BTV8, Europe had to face the emergence of BTV1, $2,4,9$, and 16, spreading in countries where the virus has never been detected before. These unprecedented outbreaks trigger the need to evaluate and compare the clinical, virological and serological features of the European BTV serotypes in the local epidemiological context. In this study groups of calves were infected with one of the following European BTV serotypes, namely BTV1, 2, 4, 9 and 16. For each tested serotype, two groups of three male Holstein calves were used: one group vaccinated against BTV8, the other non-vaccinated. Clinical signs were quantified, viral RNA was detected in blood and organs and serological relationship was assessed. Calves were euthanized 35 days post-infection and necropsied. Most of the infected animals showed mild clinical signs. A partial serological cross reactivity has been reported between BTV8 and BTV4, and between BTV1 and BTV8. BTV2 and BTV4 viral RNA only reached low levels in blood, when compared to other serotypes, whereas in vitro growth assays could not highlight significant differences. Altogether the results of this study support the hypothesis of higher adaptation of some BTV strains to specific hosts, in this case calves. Furthermore, cross-protection resulting from a prior vaccination with BTV8 was highlighted based on cross-neutralization. However, the development of neutralizing antibodies is probably not totally explaining the mild protection induced by the heterologous vaccination.
\end{abstract}

\section{Introduction}

Bluetongue virus (BTV) represents the type species of the Orbivirus genus, family Reoviridae and causes bluetongue disease (BT) in susceptible species [1,2]. BTV is usually transmitted to domestic and wild ruminants by the bite of haematophagous female midges of the Culicoides genus yet direct transmission was demonstrated at least for serotype 26 [3]. From 1998 to

\footnotetext{
*Correspondence: claude.saegerman@uliege.be

${ }^{1}$ Faculty of Veterinary Medicine, Research Unit in Epidemiology and Risk

Analysis Applied to Veterinary Sciences (UREAR-ULg), Fundamental and Applied Research for Animal and Health (FARAH) Center, University of Liege, Liege, Belgium

Full list of author information is available at the end of the article
}

2006, Europe had to face an unprecedented emergence of BTV serotypes 1, 2, 4, 9 and 16 (BTV1, 2, 4, 9, 16) throughout the Mediterranean Basin, including several countries where the virus was never detected before. August 2006 is a tipping point in BTV epidemiology, with a first detection of BTV8 in Europe Mainland [4] and a subsequent wide spread throughout Europe during the following 2 years. BTV8 emergence was easily spread through Culicoides species that were not known as the historic BTV transmission species, i.e. Culicoides obsoletus complex species [5]. This epidemic-affecting abundantly cattle whereas previous outbreaks largely occurred in small ruminants-is considered to have caused greater economic damage than any previous 
single serotype outbreak [6]. Most of the countries involved in the beginning of the BTV8 epidemic and that paid the heaviest toll were declared bluetonguefree in 2012 (Belgium, the Netherlands, Germany, France $[7,8])$.

Bluetongue virus virulence and transmission potential is not serotype driven thus outcome of the infection cannot be predicted based on the serotype alone [9]. Within a serotype, the geographical origin can be used to define topotypes with different pathogenicity. As an example, some Australian strains were reported to be less virulent than their Western counterparts [10]. The presence of competent palearctic vectors and several serotypes recently described in Europe mainland, with non-immunized livestock, trigger the need to evaluate and compare the clinical, viral and immunological features of the European BTV serotypes in cattle. In addition, since the European BTV8 showed an unusual virulence in cattle, the emergence of another serotype could take place in an area with local cattle possibly already immunized against BTV8.

Serological relationships between the different BTV serotypes were mostly established more than 25 years ago based on plaque reduction tests and cross-protection experiments in sheep [11]. It is assumed that there is partial or no cross-protection between the different BTV serotypes, therefore the need of serotype specific vaccination strategies. At the moment, a total of 27 serotypes have been recorded [12], possibly 29 [13]. As a consequence, developing and implementing multiserotype prophylactic approaches to tackle BTV is one of the major challenges in the control of the disease. Crossreactivity between BTV1 and BTV23 [14], BTV1 and BTV8 [15] or more recently between BTV16 and multivalent serum of sheep vaccinated against BTV9, 2 and 4 [16] was reported. These serotypes are however traditionally considered as poorly related.

The current study was implemented to pursue two main objectives. First, to assess and compare the virulence of some of the BTV serotypes threatening Europe mainland-namely BTV1, BTV2, BTV4, BTV9 and BTV16-in controlled conditions in calves. Second, to evaluate the extent of cross-protection granted by BTV8 vaccination in calves infected with these serotypes. In addition, in vitro humoral cross-reactivity was determined.

To these ends, each of the tested serotypes (BTV1, BTV2, BTV4, BTV9, and BTV16) was used to infect two groups of calves. One group was vaccinated against BTV8 using a commercial inactivated vaccine, and the other group was not. The clinical, pathological and virological consequences of the infection with these different serotypes, whether the animals were vaccinated or not, were compared, and serological relationships were assessed.

\section{Materials and methods \\ Animals}

Animals were treated in accordance with the International Guiding Principles for Biomedical Research Involving Animals, as issued by the Council for the International Organizations of Medical Sciences and EU Directive 2010/63/EU for animal experiments.

A total of 35 Holstein male calves, about 5.5-6 months old, were used. All the selected animals were tested seronegative (ELISA and seroneutralization) and non viraemic (RTqPCR) for BTV and Bovine herpesvirus 1 (BoHV1). In addition these calves were also born from BTV naïve dams (seronegative and RTqPCR negative). They were introduced in an insect secured BSL3 facility 1 week before the beginning of the experiment to allow their acclimatization.

\section{Virus}

BTV1, BTV2, BTV4, BTV9 and BTV16 were all derived from the reference strains of the Onderstepoort Veterinary Institute. These strains underwent further passages at The Pirbright Institute (TPI); passage history is available at the RNAs and Proteins of dsRNA Viruses [17]. The BTVs were subsequently passaged at Sciensano, Ukkel, Belgium (formerly CODA-CERVA) between two and four times on BHK-21 cells. BTV8 originated from a field sample (BEL2006/01) afterwards passaged 6 times in BHK-21. Each serotype has been tested by RTqPCR specific of the serotypes used in the study to rule out potential contamination of the inocula.

\section{Experimental design}

Five animals were kept as environmental control, and were inoculated with Dulbecco's Modified Eagle Medium (DMEM, Life Technologies, Gent, Belgium). Groups were identified by their vaccination status against BTV8 ( $\mathrm{V}_{-}$or $\mathrm{NV}_{-}$, respectively vaccinated and non-vaccinated) followed by the subsequently inoculated BTV serotype (BTV1, BTV2, BTV4, BTV9 or BTV16). For each tested serotype, two groups of three calves each were used. The animals from the first group were vaccinated against BTV8 (BTVPUR AISap 8, Merial, Lyon, France) following manufacturer instructions, with the second vaccine injection 33 days before challenge. In the other group the animals were not vaccinated.

To be infected, the animals received between 2.5 and $4 \mathrm{~mL}$ of inoculum, properly diluted to a normalized titre of $10^{6} \mathrm{TCID}_{50}$ /animal. Inoculations were realised through the subcutaneous route, on the left side of the neck. Daily examination of the calves included temperature and 
clinical signs monitoring for 35 days post-infection (dpi). The severity of the infection was quantified by calculating clinical scores per system and per animal, leading to overall clinical scores by groups and animal, following a standardised clinical form adapted from Saegerman et al. [18]. Briefly, clinical signs were summed up according to their nature (general signs versus localised clinical signs on muzzle, mouth, limbs and eyes) and intensity (crust, ulcerations or necrosis, oedema or inflammation). The calves were euthanatized at 35 dpi by captive bolt stunning followed by bleeding. Extensive necropsy has been performed, and spleen, thymus, prescapular and mesenteric lymph nodes, testicle and lung were sampled from infected and control calves, to detect BTV RNA by RTqPCR.

\section{BTV RNA detection}

Viral RNA extraction from the blood was achieved using the QIAamp Viral RNA Mini Kit (Qiagen, Antwerp, Belgium). In the organs, about $100 \mathrm{mg}$ of tissues per organ were processed; viral RNA extraction was performed using Trizol reagent according to the manufacturer's instructions (Gibco Invitrogen, UK). Viral RNA denaturation and reverse transcription were adapted from previously published protocols [19] with slight modifications, as denaturation was realised in presence of random hexamers. Serotype specific RTqPCR assays were carried out for BTV1, BTV2, BTV4, BTV8, BTV9 and BTV16 using LSI VetMAX European BTV Typing Real-Time PCR Kits (ThermoFisher Scientific, Gent, Belgium), following manufacturer's instructions.

RTqPCR reactions were run on a CFX96 Touch $^{\mathrm{TM}}$ RealTime PCR Detection System (Bio-Rad Laboratories N.V., Temse, Belgium) using the following cycling conditions: heat inactivation at $95^{\circ} \mathrm{C}$ for $10 \mathrm{~min}, 50$ cycles consisting of denaturation at $95{ }^{\circ} \mathrm{C}$ for $15 \mathrm{~s}$ and annealing/elongation at $58^{\circ} \mathrm{C}$ for $30 \mathrm{~s}$.

To allow absolute quantification of the viral RNA content in blood and organ samples, standard curves of serotype specific plasmids (pGEM ${ }^{\circledR}-\mathrm{T}$ Easy Vector, Promega, The Netherlands), carrying the target part of the segment 2 , were constructed. Quantification was expressed in cDNA copy number $/ \mathrm{mL}$ of blood.

\section{Anti-BTV antibodies detection}

For each tested serotype neutralizing antibodies (Abs) were titrated by seroneutralization (SNT). Two-fold serial dilutions of the sera $(1: 10-1: 1280)$ were tested in the presence of $100 \mathrm{TCID}_{50}$ of BTV, as previously described [20]. The neutralizing antibody titre was defined as the reciprocal of the serum dilution causing a $50 \%$ reduction in cytopathic effect. Serum of all the animals has been tested at several time points with the homologous virus.
Anti-VP7 antibodies circulation was also evaluated using a commercial competitive ELISA kit (ID Screen ${ }^{\circledR}$ Bluetongue Competition ELISA kit, ID Vet, France). Results were expressed as \% negativity (PN) compared to the negative kit control and transferred to a positive, doubtful or negative result according to the cut-off settings provided by the manufacturer $(\mathrm{PN} \leq 35$ is positive; $35<\mathrm{PN} \leq 45$ is doubtful; $\mathrm{PN}>45$ is negative). As these cut-off values were rather designed for screening purposes [21], the cut-off suggested by Vandenbussche et al. [19] (negative when $\mathrm{PN}>66$ ) has been also considered as a tool for individual diagnostic, with respect of the limited number of animals.

\section{Haematology}

Starting during the acclimatization period and until the end of the experiment, a complete haemogram (Vet ABC, SCIL animal care company, France), including total leukocytes, monocytes, lymphocytes, neutrophils, eosinophils and basophils was performed on EDTA blood samples on a regular basis.

\section{Cross-neutralization assay}

In each non-vaccinated group, the individual serum sample with the highest homologous neutralizing titre has been selected and subsequently tested by SNT against all the other inoculated BTV serotypes. In order to avoid potential bias due to low humoral response against any of the serotype, heterologous neutralization results for each tested serotypes were expressed as a percentage of the titre reached when the immunised serum was tested with the homologous serotype. BTV8 immune serum was obtained from an experimentally infected heifer in a previous study [22].

\section{In vitro kinetic growth of BTV serotypes}

In vitro growth properties of the $6 \mathrm{BTV}$ serotypes (i.e. BTV1, BTV2, BTV4, BTV8, BTV9 and BTV16) used in this study were compared using their replication kinetics in VERO cell culture, following a protocol adapted from Dal Pozzo et al. [23]. Briefly, all the inocula were used in a one-step growth assay, with confluent VERO cells, at a multiplicity of infection (m.o.i.) of 0.05. After $0,8,24,48,72,96$ and $120 \mathrm{~h}$ incubation, the supernatant was removed and stored $-80{ }^{\circ} \mathrm{C}$. For each time point, the virus titre was determined at least in triplicate by plaque assay [24] and expressed as $\log \mathrm{TCID}_{50} / \mathrm{mL}$.

\section{Infectivity}

For each serotype, the original inoculum plus two serial 1:10 dilutions were tested by RTqPCR. Knowing the infectious titre of each inoculum, for each serotype a mean ratio of segment $2(\mathrm{~S} 2)$ cDNA/TCID ${ }_{50}$ was then 
calculated. The infectious titre of the blood samples was then extrapolated using RTqPCR results multiplied by the mean segment $2 \mathrm{cDNA} / \mathrm{TCID}_{50}$ ratio and expressed as $\mathrm{TCID}_{50} / \mathrm{mL}$, for each tested time points. $\mathrm{TCID}_{50} / \mathrm{mL}$ titres were then converted in PFU/mL to assess the level of infectivity of each serotype based on the estimate of the minimal PFU/mL required to infect vector Culicoides according to Dungu et al. [25].

\section{Statistical analysis}

For viraemia levels and infectivity assessment between vaccinated and non-vaccinated groups, the comparison of quantitative parameters was performed using pair-wise $t$ tests or Welch test, as appropriate. One-way ANOVA with post hoc Tukey test were used to analyse haematological values within the same group with respect to baseline values at $0 \mathrm{dpi}$. Differences between control and infected groups at the same time-point were analyzed using a two-way mixed model ANOVA with Bonferroni post-test. Two-way mixed model ANOVA were calculated using the statistical analysis program GraphPad Prism version 5.01 for Windows (GraphPad Software, San Diego California USA). Other statistical analyses were realized using the $\mathrm{R}$ software/environment (R-3.2.1, R Foundation for Statistical Computing). For all tests, $P$ values $<0.05$ were considered significant.

\section{Results}

\section{Clinical examination}

Two calves from the control group showed 1-2 days-lasting hyperthermia between 6 and $12 \mathrm{dpi}$, without other systemic problem or clinical signs evocative of bluetongue disease. In infected animals, clinical signs were mild, and would probably go unnoticed in the field, as appetite was conserved and general condition unchanged. Nevertheless, typical bluetongue clinical signs were observed, including facial oedema, swelling and reddening of the odontoid papillae, crusts and erosions at the muco-cutaneous junction, nasal discharge and purulent conjunctivitis. V_BTV9 group and NV_BTV1 group clinical scores were significantly higher than control group $(P<0.05)$. V_BTV9 and NV_BTV16 groups had a significantly higher clinical score than their counterparts infected with the same serotype but different vaccination status. There were no significant differences between clinical scores of other infected groups when compared to each other, to the control group or when comparing groups infected with the same serotype but with different vaccination status (Figure 1). A great individual variability was observed in the clinical outcomes within each group, as in 6 out of 10 infected groups, one single animal totalized $50 \%$ or more of the total clinical score of the group.

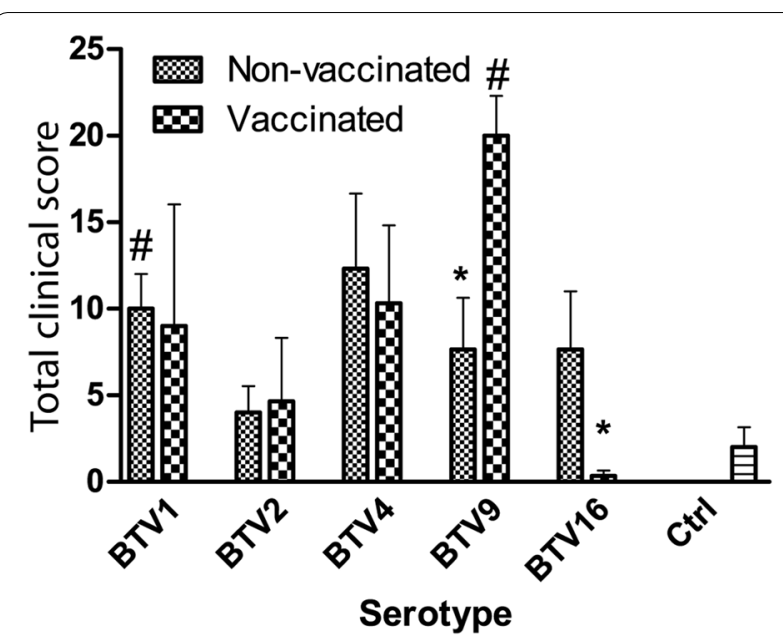

Figure 1 Total clinical scores by group and vaccination status. Error bars represent standard error of the mean. ${ }^{*} P<0.05$ between vaccinated and non-vaccinated groups infected with the same serotype. ${ }^{\#}<0.05$ compared to the control group.

\section{BTV RNA detection}

No viral RNA was detected in any of the control animals at any time point. Inoculated animals showed different viraemia patterns depending on the inoculated serotype and their vaccination status. The earliest BTV RNA detection in the blood occurred at $1 \mathrm{dpi}$ in $\mathrm{NV}_{-}$and V_BTV1 groups. The latest onset of viraemia occurred in one calf of V_BTV2 group at $11 \mathrm{dpi}$. In calves infected with serotypes 2 and 4 BTV RNA could only be detected inconsistently and RNAemia reached moderate levels when compared to calves infected with BTV1, 9 and 16 (Figure 2). After the challenge of vaccinated animals, the Log copy number of viral RNA was significantly lower in BTV2 and BTV4 groups when compared to BTV9 and BTV16 groups (Two way ANOVA with repeated measures, $P<0.004)$. In addition, BTV1 RNA detection was also significantly lower than BTV9 $(P<0.013)$. After the challenge of non-vaccinated animals viral RNA detection was significantly lower in BTV2 and BTV4 groups when compared with BTV9 and BTV1 groups $(P<0.003)$, and BTV4 RNA detection was significantly lower than BTV16 $(P<0.005)$. Regarding homologous serotypes, only BTV1 showed a lower RNA detection in V group versus NV group $(P<0.016)$. Vaccinated animals had an RNAemia ranging from 79.4 to $95.5 \%$ of the max RNAemia level of the non-vaccinated animals at the viraemic peak. At the end of the experiment viral RNA was still detectable in $40 \%$ of the vaccinated animals versus $73 \%$ in the non-vaccinated calves. However this difference was not significant $\left(\chi^{2}, P=0.065\right)$. 


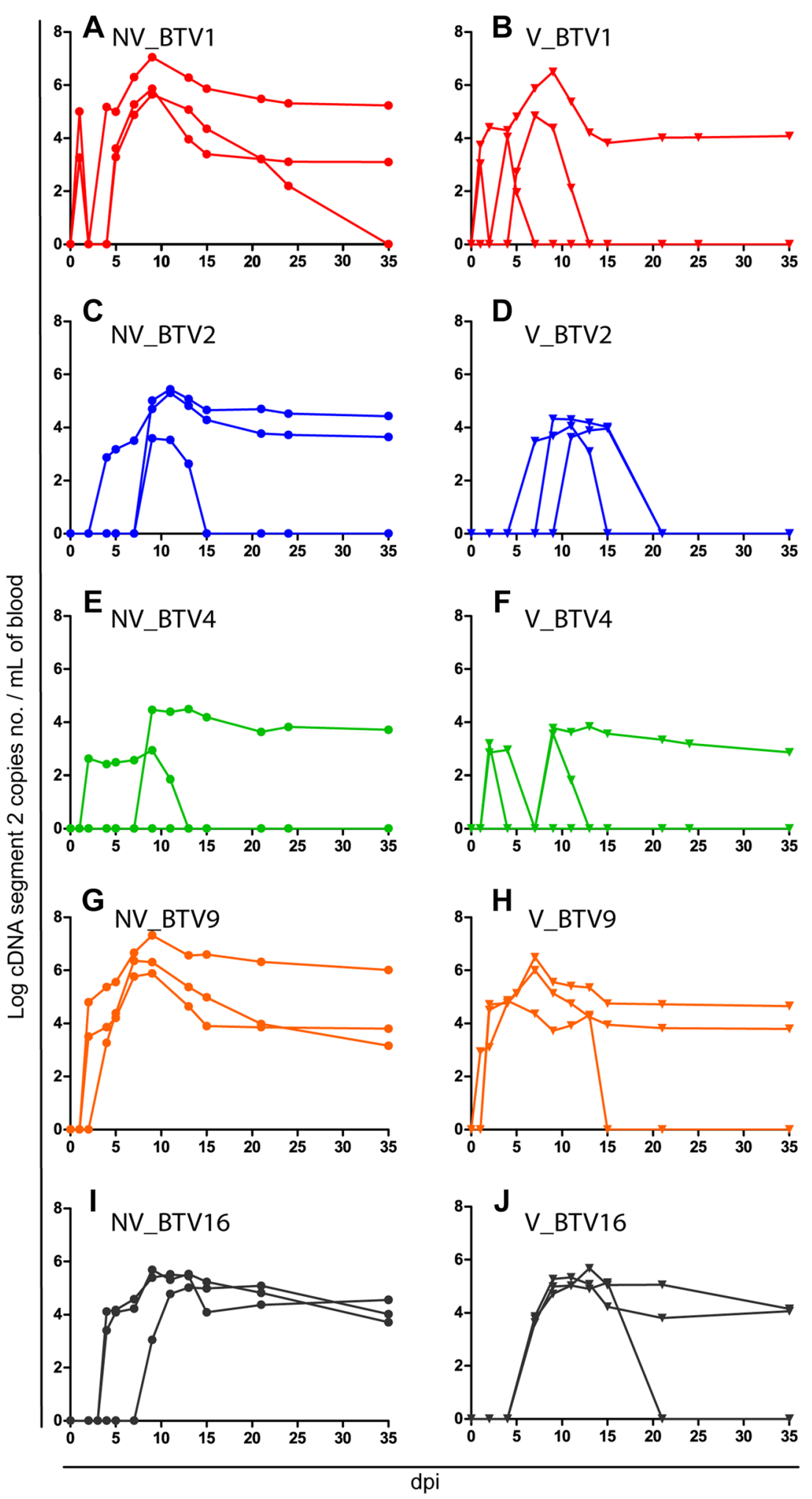

Figure 2 Individual daily viral genome load in calves' blood. Results are expressed as the Log copies of BTV segment $2 \mathrm{cDNA}$ per $\mathrm{mL}$ of blood. A and B BTV1; C and D BTV2; E and F BTV4; G and $\mathbf{H}$ BTV9; $\mathbf{I}$ and $\mathbf{J}$ BTV16. C, E, G and $\mathbf{I}$ are non-vaccinated groups whereas B, D, F, H and $\mathbf{J}$ are vaccinated groups; dpi: day post-infection. 


\section{Anti-BTV antibodies detection}

All the inoculated animals produced homologous neutralizing antibodies that started generally to be detected two to 3 weeks post-infection (Figure 3). In previously BTV8 vaccinated calves, the rise of neutralizing antibodies against the virus serotype used in the challenge was earlier detected and reached higher levels compared to non-vaccinated calves however only significant for BTV2 infected animals $(P<0.035)$. In vaccinated animals, anti-BTV8 neutralizing antibodies were contemporaneously circulating (Figures 3B-J) and anti-BTV8 titres were significantly higher than in $\mathrm{NV}$ animals for all serotypes. Whereas no significant increase in anti-BTV8 neutralizing antibodies could be detected in non-vaccinated animals, vaccinated ones from groups inoculated with BTV2 and 16 underwent a slight boost in anti-BTV8 neutralizing antibodies titres, despite the heterologous nature of inoculated serotype $(P<0.006)$.

Neutralizing antibodies titres had no correlation with viral RNA detection level $(r=0.12, P=0.11)$ and maximal SNT titres had no correlation with maximal BTV RNA copy number $(r=0.09, P=0.63)$.

The cELISA kit managed to detect Anti-VP7 antibodies for each tested serotype. The time of seroconversion was in line with previously published data [20, 26, 27], between 10 and $21 \mathrm{dpi}$ for all serotypes (Figure 4). By the time of inoculation, 2 V_BTV2 and 2 V_BTV4 calves had a PN above the positivity threshold (thus considered negative) determined by the manufacturer $(\mathrm{PN} \leq 35)$, however considered positive if taking into account of the threshold defined by Vandenbussche et al. [19] ( $\mathrm{PN} \leq 66)$. All these 4 animals had PN that reached values under 35 within $7 \mathrm{dpi}$.

\section{Haematology}

Monocyte counts increased shortly after infection in all groups but control animals independently of their vaccination status. The increase started between 4 and $11 \mathrm{dpi}$, peaked at 15 or $18 \mathrm{dpi}$ and then came back to baseline levels by $35 \mathrm{dpi}$ (Figure 5). All NV groups showed peaks significantly higher than baseline value $(0 \mathrm{dpi})$ or control value at the same time point (Figure $5 \mathrm{~A}, P<0.05$, two way ANOVA with repeated measures) whereas in $\mathrm{V}$ groups only peaks of V_BTV1, BTV2, and BTV9 were significantly higher (Figure $5 \mathrm{~B}, P<0.05$, two way ANOVA with repeated measures).

Lymphocyte count followed a different trend, decreasing in the first dpi, from about 4-11 dpi, then recovering and even significantly exceeding baseline values (Figure 5D, V_BTV4: $18 \mathrm{dpi}, P<0.05$, two way ANOVA with repeated measures) or control values at the same time point (Figures 5C and D, NV_BTV2: $25 \mathrm{dpi}$ and $\mathrm{V}_{-}$ BTV16: 21, 25 and 35 dpi, $P<0.05$, two way ANOVA with repeated measures).

\section{Necropsy and BTV RNA detection in organs}

At the necropsy, lesions were sporadically reported, including haemorrhage and petechial haemorrhage on several lymph nodes, endocardic suffusion, abscesses and petechial haemorrhage in the lung, and a slight haemorrhage in the wall of the pulmonary artery of one calf in the NV_BTV9 group.

No viral RNA could be detected in any organs of the animals of the BTV2 and BTV4 groups, whether they were vaccinated or not (Table 1 ). The proportion of positive organs was significantly higher in BTV9 infected groups (pairwise Fisher test, $P<0.002$ ). However there was no significant difference between BTV9 V and NV groups regarding organ detection $(P=0.075)$. Considering all serotypes all together, viral RNA was most commonly detected in prescapular lymph node (Table 1). In vaccinated animals infected with BTV9, detection of BTV RNA in organs was associated with an Odds Ratio of $0.16(P<0.03,[0.029-0.691])$.

\section{Cross neutralization assay}

Different degrees of in vitro cross neutralization could be found using all immunized sera (Table 2). However, immunized sera of BTV2 and BTV9 showed the least degree of in vitro cross neutralization against the other tested viral serotypes. On the contrary, BTV8 immune serum had a higher neutralization effect in vitro on the growth of BTV4, reaching a titre equal to $25 \%$ against BTV4 when compared to the titre reached against BTV8 itself. BTV1 immune serum reached a similar level of partial seroneutralization against BTV8. A lesser cross neutralization has been reported with the BTV16 serum towards BTV1 virus (Table 2).

\section{In vitro kinetic growth of BTV serotypes}

The mean virus titres measured for each serotype at the different time points were compared to all the other serotypes using a two-factor ANOVA with repeated measures on one factor, showing no significant difference between the different kinetic growth curves $(P=0.41$, Figure 6).

BTV1, 2, 6 and 16 had earlier replication as cytopathic effect (CPE) has been reported since $8 \mathrm{~h}$ post-infection (hpi), whereas BTV4, 8 and 9 showed CPE starting at 24 hpi.

\section{Infectivity}

At viraemic peak S2 copies number ranged from $10^{6.52( \pm 0.73)}$ for NV_BTV9 to $10^{3.39}{ }^{( \pm 1)}$ for NV_BTV4 

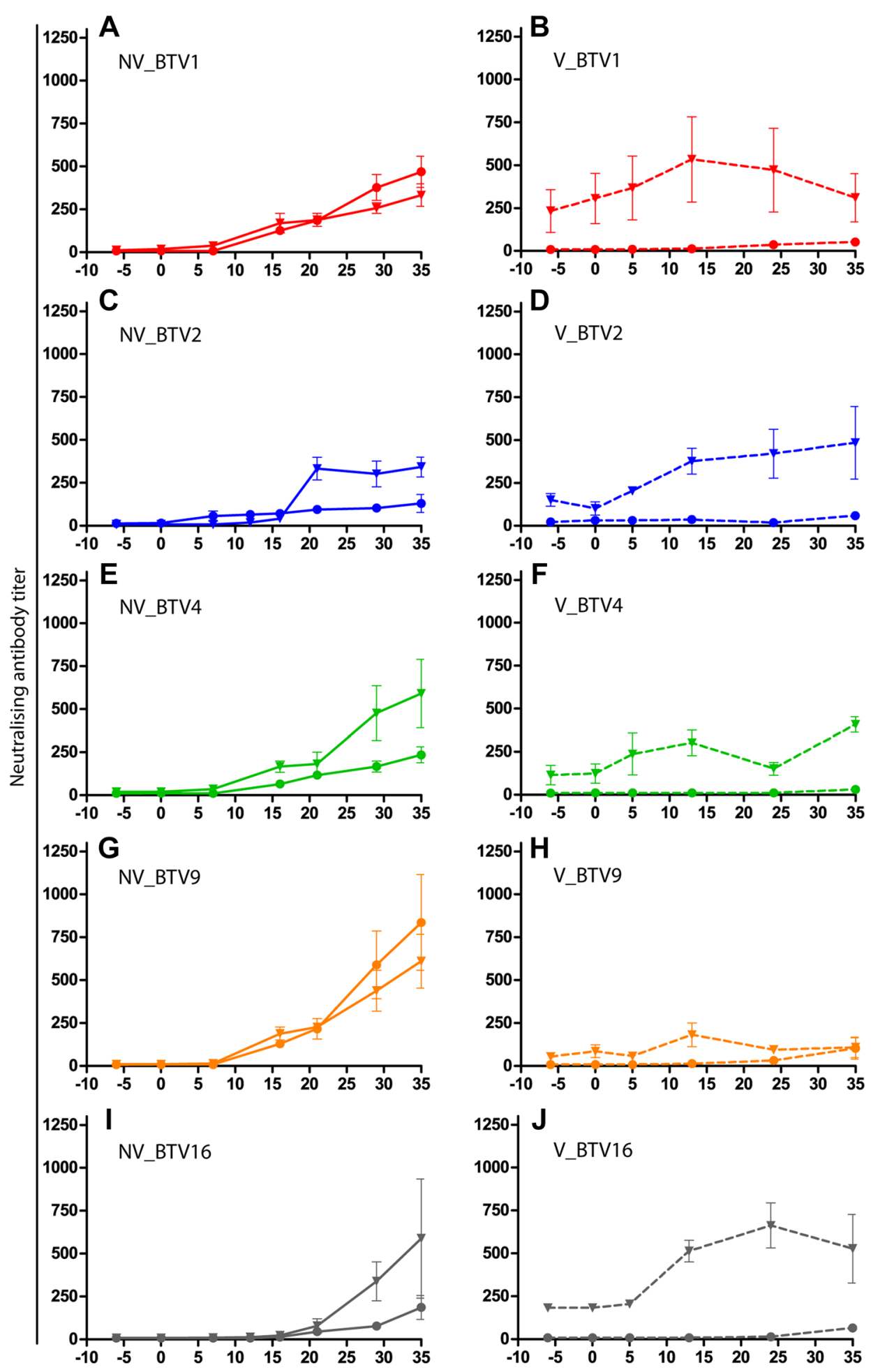

dpi

Figure 3 Evolution of neutralising antibodies titres against BTV8 and homologous inoculated serotypes. A, C, E, G and I (full lines): mean neutralising antibodies titres per group against respectively BTV1, 2, 4, 9 and 16. In each panel vaccinated (triangle) and non-vaccinated (filled circle) groups are represented. $\mathbf{B}, \mathbf{D}, \mathbf{F}, \mathbf{H}, \mathbf{J}$ (dashed lines): mean neutralising antibodies titres against BTV8 in vaccinated (triangle) and non-vaccinated (filled circle) animals in respectively BTV1, 2, 4, 9 and 16 inoculated groups. Error bars represent standard error of the mean. dpi: day post-infection. 

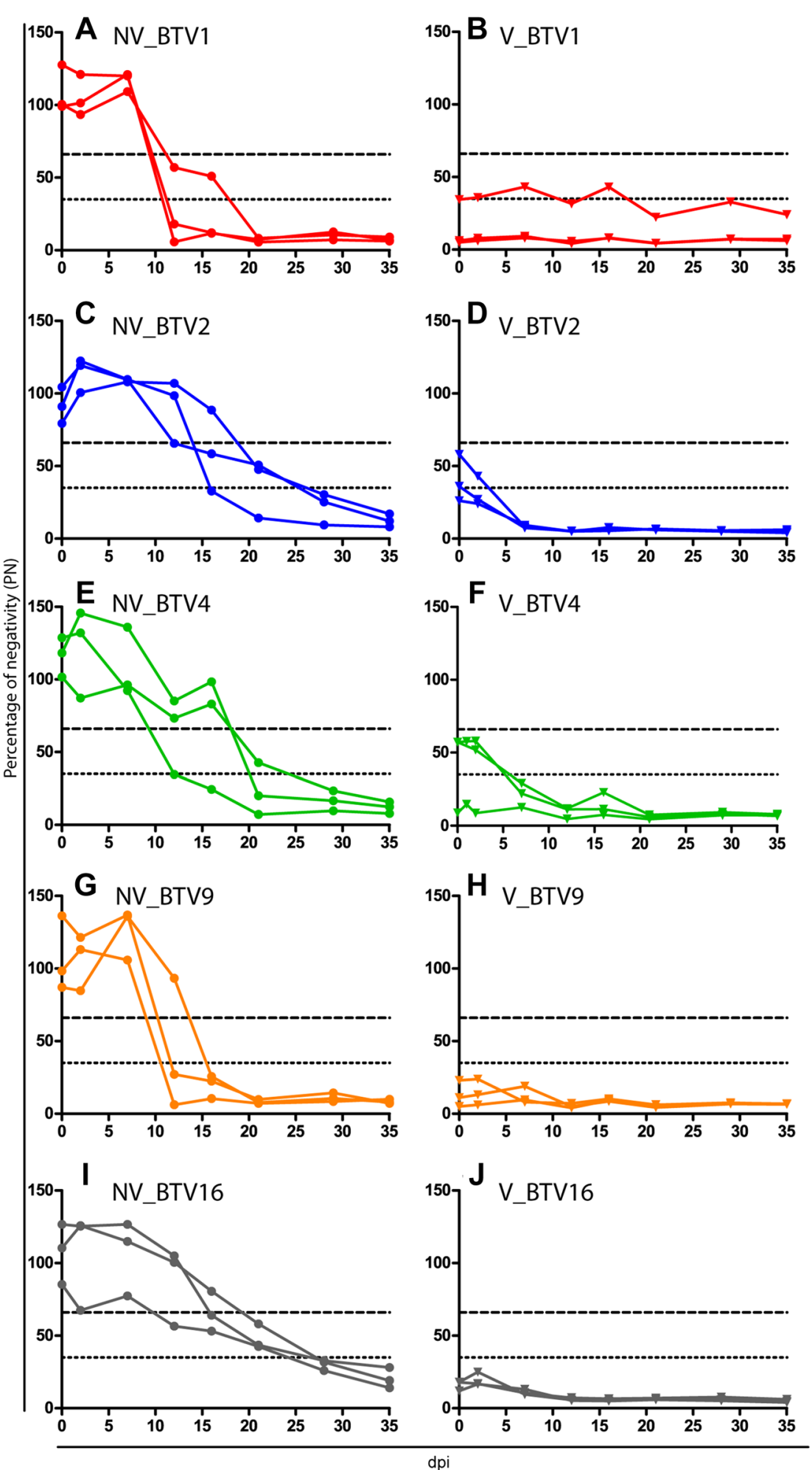

---. cut-off at 66 PN

-.... cut-off at $35 \mathrm{PN}$ (manufacturer's instruction)

Figure 4 Evolution of serogroup specific antibodies. The results are presented for each animal as the percentage of negativity (PN) obtained in the competitive ELISA. Data for non-vaccinated (filled circle) and vaccinated (triangle) animals are shown for BTV1 (A, B), BTV2 (C, D), BTV4 (E, F), BTV9 $(\mathbf{G}, \mathbf{H})$ and BTV16 $(\mathbf{I}, \mathbf{J})$. Dotted line represents the cut-off value recommended by the manufacturer and dashed line the one suggested by Vandenbussche et al. [18]. dpi: day post-infection. 

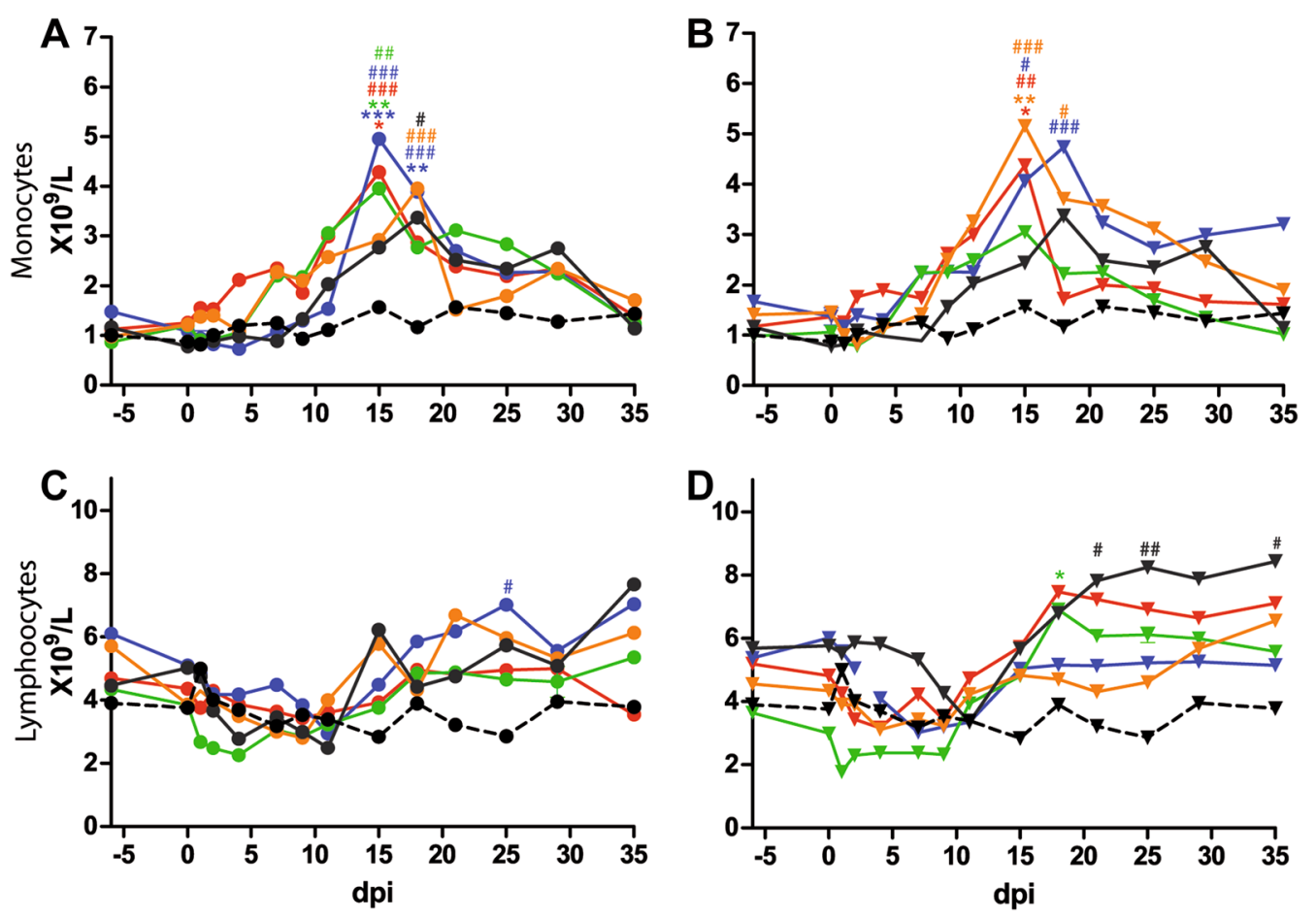

- BTV1 - BTV2 - BTV4 - BTV9 - BTV16 --. Ctrl • Non-vaccinated V Vaccinated

Figure $\mathbf{5}$ Lymphocytes and monocytes cell counts. Mean monocytes (A and $\mathbf{B})$ and lymphocytes $(\mathbf{C}$ and $\mathbf{D})$ cell counts in non-vaccinated $(\mathbf{A}$ and $\mathbf{C}$ ) and vaccinated animals ( $\mathbf{B}$ and $\mathbf{D}$ ), expressed as $10^{9} \mathrm{cell} / \mathrm{s} / \mathrm{L}$. dpi: day post-infection. For a better readability error bars were removed. ${ }^{*} P<0.05$; ${ }^{* *} P<0.01$ and ${ }^{* * *} P<0.001$ between vaccinated and non-vaccinated groups infected with the same serotype. ${ }^{*} P<0.05 ;{ }^{\# \#} P<0.01 ;{ }^{\# \#} P<0.001$ compared to the control group.

Table 1 BTV RNA detection in organs at necropsy

\begin{tabular}{|c|c|c|c|c|c|c|c|}
\hline & Calf ID & Spleen & Mesent. LN & Prescap. LN & Thymus & Testicle & Lung \\
\hline \multirow[t]{3}{*}{ NV_BTV1 } & 169 & NEG & NEG & 7.41 & NEG & NEG & NEG \\
\hline & 1004 & NEG & NEG & 6.27 & NEG & 3.33 & NEG \\
\hline & 6712 & NEG & NEG & 4.92 & NEG & NEG & NEG \\
\hline \multirow[t]{3}{*}{ V_BTV1 } & 2038 & NEG & NEG & 0.40 & NEG & NEG & NEG \\
\hline & 2044 & 1.42 & NEG & 18.96 & NEG & NEG & NEG \\
\hline & 5093 & NEG & NEG & NEG & 0.15 & NEG & NEG \\
\hline \multirow[t]{3}{*}{ NV_BTV9 } & 1058 & NEG & 4.73 & 57.43 & 28.61 & 2.23 & 0.57 \\
\hline & 2071 & 12.22 & 4.36 & 18.78 & NEG & 1.89 & 1.30 \\
\hline & 3045 & 2.00 & 1.14 & 5.72 & 0.52 & 4.59 & NEG \\
\hline \multirow[t]{3}{*}{ V_BTV9 } & 2740 & NEG & 7.40 & NEG & 24.48 & 1.71 & NEG \\
\hline & 3934 & 0.96 & 0.88 & 2.09 & NEG & NEG & NEG \\
\hline & 4935 & 11.84 & NEG & 9.46 & NEG & NEG & NEG \\
\hline \multirow[t]{3}{*}{ NV_BTV16 } & 5583 & NEG & NEG & 2.25 & NEG & NEG & NEG \\
\hline & 8606 & NEG & NEG & NEG & NEG & NEG & NEG \\
\hline & 9535 & NEG & 0.23 & NEG & 17.34 & NEG & NEG \\
\hline \multirow[t]{3}{*}{ V_BTV16 } & 2461 & NEG & NEG & NEG & NEG & NEG & NEG \\
\hline & 3150 & NEG & NEG & NEG & 97.22 & NEG & NEG \\
\hline & 5077 & NEG & NEG & 2.70 & NEG & NEG & NEG \\
\hline
\end{tabular}

Results are expressed a BTV RNA copy number per $100 \mathrm{mg}$ of tissue.

No positive detection could be found in any tested sample in BTV2 and BTV4 vaccinated or non-vaccinated groups.

NV_: non vaccinated group; $V_{-}$: vaccinated group; NEG: negative result; Mesent. LN: mesenteric lymph node; Prescap. LN: prescapular lymph node. 
Table 2 Percentages of relative homologous and heterologous seroneutralization titers

\begin{tabular}{|c|c|c|c|c|c|c|}
\hline \multirow[t]{2}{*}{ Immunised serum } & \multicolumn{6}{|c|}{ BTV serotype } \\
\hline & BTV1 & BTV2 & BTV4 & BTV8 & BTV9 & BTV16 \\
\hline Control & 0.52 & 1.11 & 0.55 & 0.44 & 0 & 3.54 \\
\hline BTV1 & 100 & 1.11 & 8.85 & 25 & 0 & 3.54 \\
\hline BTV2 & 1.3 & 100 & 3.15 & 0.44 & 0 & 3.54 \\
\hline BTV4 & 0.65 & 0.88 & 100 & 0.44 & 0 & 12.5 \\
\hline BTV8 & 10.36 & 12.5 & 25 & 100 & 6.25 & 3.54 \\
\hline BTV9 & 2.61 & 3.1 & 0.77 & 0.44 & 100 & 3.54 \\
\hline BTV16 & 18.34 & 12.39 & 0.83 & 0.44 & 0 & 100 \\
\hline
\end{tabular}

(Figure 7A), which correspond to a titre of $10^{3.74}( \pm 0.42)$ TCID $_{50} / \mathrm{mL}$ for NV_BTV9 group and $10^{0.58}( \pm 0.11)$ $\mathrm{TCID}_{50} / \mathrm{mL}$ for NV_BTV4 (Figure 7B). Only BTV9 and BTV16 groups had consistently max viraemia higher than $10^{3155} \mathrm{TCID}_{50} / \mathrm{mL}$ (threshold value under which oral infection of Culicoides is supposed to be impossible according to Dungu et al. [25]) in all animals. Amongst BTV1 infected calves only NV_BTV1 calf 0169 had a max viraemia above the threshold. No animals in the BTV2 or BTV4 groups had a viraemia above $10^{3155}$ $\mathrm{TCID}_{50} / \mathrm{mL}$ whichever was the considered time point or vaccination status.

\section{Discussion}

In this study BTV inoculation resulted from asymptomatic affection to mild clinical signs. Although controversial $[20,28,29]$ the passage history of the virus used in the current study could influence the clinical expression

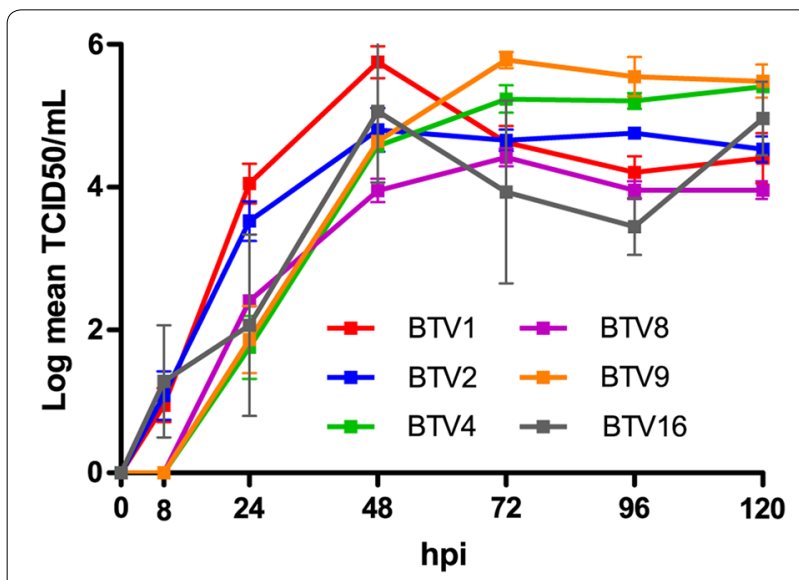

Figure 6 In vitro kinetic growth of BTV1, 2, 4, 9, and 16. Growth curves of BTV1, 2, 4, 8, 9 and 16 in VERO cells. Cells were infected at a $\mathrm{MOl}$ of 0.05 and supernatant collected at 8, 24, 48, 72, 96 and $120 \mathrm{~h}$ post-infection (hpi). Then supernatants were titrated on VERO cells by end-point dilution assay and expressed as the $\log \left(\mathrm{TCID}_{50} / \mathrm{mL}\right)$. Each growth curve has been established independently at least in triplicate for each serotype. of the disease. Individual susceptibility could be another explanation [1].

Unlike in many other viral diseases [30-32], it was not possible to demonstrate a statistically significant relation between level and duration of viraemia, and clinical presentation. However this is not surprising in BTV infection, as RNAemia lasts longer in cattle than in sheep despite the more severe outcome in the latter species [33]. Furthermore, BTV clinical picture in cattle is usually subtle and does not allow to make any correlation with the viral RNA detection in the blood.

On the other hand, BTV replication level has been correlated to the adaptation of the virus to the host [34]. In this study and based on the levels of viral RNA detection serotypes were ranked as follows from the most to the less adapted in calves: BTV9, 1, 16, 2 and 4 in non-vaccinated groups, and BTV9, 16, 1, 2 and 4 in vaccinated ones. The limited circulation of BTV2 and BTV4 RNA in blood might explain the absence of positive detection in organs at necropsy. The hereinabove suggested host adaptation ranking based on BTV serotypes might involve non-serotype specific virulence factors, in line with findings from Caporale et al. [35].

For standardization purposes the same doses were inoculated, regardless of the serotype. It has to be stressed that different BTV strains or serotypes, as a consequence of their large variability, their origin, could indeed be non-equivalently adapted to their hosts. Dal Pozzo et al. described a dominance of BTV8 in cattle when compared to BTV1 and BTV15 [23]; North American serotype 10 replicates more efficiently in sheep than serotype 17 [36], and comparing BTV1 and BTV15, BTV1 seems to be better adapted to sheep whereas BTV15 is better adapted to cattle [34]. In addition, the modified live vaccine (MLV) required doses to grant protection in sheep have been determined to be different depending on the considered serotype [37]. Indeed the low replication level of BTV4 and BTV2 observed in this study might rely on an inoculation 

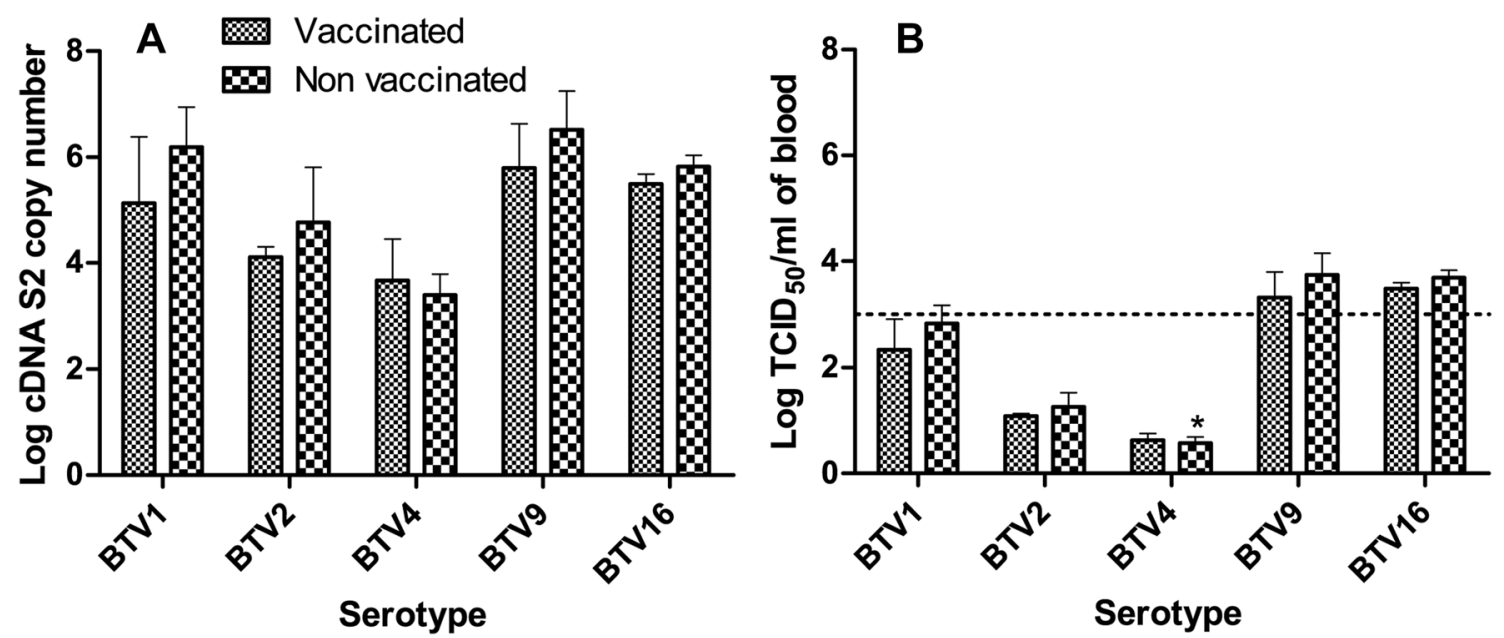

Figure 7 Mean S2 cDNA copy number and infectivity at viraemic peak. A S2 cDNA mean copy number at viraemic peak by tested serotype and vaccinated status. B Infectivity at viraemic peak, expressed as mean Log $T_{C} C_{50} / \mathrm{mL}$ of blood titre by tested serotype and vaccinated status. Dotted line represents the classical threshold of $10^{3155} \mathrm{TCID}_{50} / \mathrm{mL}$ required to allow BTV transmission to vector Culicoides. * For NV_BTV4, one animal had no detectable viraemia at all was excluded from calculation. Error bars represent standard deviation.

dose insufficient for these serotypes and support the hypothesis of a poor adaptation to cattle.

Amongst the serotypes used in this study, Erasmus described serolological relationship, based on crossprotection tests in sheep or heterotypic antibody responses, between serotypes 2 and 1, 1 and 9, and 9 and 4; serotypes 8 and 16 being quite serologically isolated [11]. In the current study cross neutralization tests revealed moderated antigenic relationships mainly between serotypes 4 and 8,1 and 8 and to a lesser extent 2 and 9. Partial cross neutralization has been previously reported between serotypes 1 and 8 [15]. The discrepancies among the above mentioned studies have to be interpreted carefully, as the origin of the used isolates varies greatly, from African strains to European field isolates. In addition, the intra-serotype VP2 nucleotide sequence variation can be up to more than $30 \%$ [38]. The quasispecies nature of BTV, its evolution through genetic drift and founder effect could explain the divergences between VP2 amino acids sequences and in vitro cross neutralization assays.

In this study the serological cross-reactivity with BTV8 was limited to BTV4 and BTV1. Consequently, the differences observed in the course of the current experiment between vaccinated and non-vaccinated groups are most likely unrelated to humoral immunity. Numerous studies have described the importance of cell-mediated immunity in the course of BTV infection [14, 39]. Cellmediated immunity is suggested to rely to an important extent on non-structural proteins [40]. Despite nonstructural proteins not being part of the viral particles used to produce inactivated vaccines, vaccinated animals were reported to develop antibodies against NS proteins [41]. Therefore, in this study, the shorter RNAemia and lower BTV detection frequency in organs of the vaccinated animals might reflect a partial NS proteins based protection. In addition, VP7 peptides have also been shown to be recognized by CTL in natural host and are considered to share similar sequences for several BTV serotypes [42]. This might be one of the underlying mechanisms that could explain the partial cross-protection of BTV1 immunization against BTV23 challenge described by Umeshappa et al. [14]. This is not contradictory to the findings of the present study, as BTV8 is as remotely related to the other European tested serotypes than BTV1 is related to BTV23, with respect to Erasmus description [11].

In our study no differences were observed among the haematology parameters measured after challenge among vaccinated and non-vaccinated groups. Monocytosis starting from $4 \mathrm{dpi}$ and can be directly linked to BTV infection which induces transcriptional activation of bovine monocyte-derived macrophages [43]. The increase of monocyte count in infected cattle might be part of the mechanisms explaining the moderate clinical picture in bovine, by contrast to the severity of the disease in sheep [44]. Indeed, differences in BTV pathogenesis in sheep and cattle were reported to be related to different production levels of vasoactive mediators [44]. Simultaneous in vivo experimental infection of cattle and sheep could be carried out along with a detailed characterization of the cytokines produced in each species to clarify this hypothesis. 
The minimum level of required viraemia to infect a vector has been established for several arthropod borne pathogens of major concern, like West Nile Virus [45], Dengue virus [46] or Chikungunya virus [47]. For BTV, MLVs are expected to lead to a viraemia lower than $10^{3} \mathrm{PFU} / \mathrm{mL}$, which is about $10^{3155} \mathrm{TCID}_{50} / \mathrm{mL}$, supposed to prevent oral infection of Culicoides [48], even if it has been clearly reported that many MLVs could give raise to higher titres in experimental conditions and possibly lead to MLV circulation in the field in Europe [49, 50]. In the current experiment, only BTV9 and BTV16 infection could reliably reproduce a viraemia above $10^{3155} \mathrm{TCID}_{50} / \mathrm{mL}$ at some points. It is however important to stress that the putative $10^{3155} \mathrm{TCID}_{50} / \mathrm{mL}$ threshold is largely discussed and remains debatable. End-point titration relies on the cell-lines used and on the time of incubation before staining, both critical parameters that have no gold standard. Therefore, although useful within a study itself, direct comparison of end-point titration values from different sources would provide not much more than coarse approximation of infectivity potential. In addition, it has been reported on several occasions that vector could clearly acquire BTV from animals with a lower viraemia, sometimes even undetectable through classical isolation techniques [51, 52]. Moreover, viraemia levels only make epidemiological sense in the light of the considered serotype or strain [45] and vectors biology, i.e. biting rates and oral susceptibility, as these parameters are species dependent and likewise population dependent [53]. These results also highlight the interest of using natural host species; indeed the tested serotypes had in VERO cell culture replication properties that did not significantly differ whereas in cattle in the current study BTV1, 9 and 16 appear to be better adapted to cattle than BTV2 and BTV4. In addition, Coetzee et al. recently reported the absence of correlation between replication levels in VERO cells and virulence in ruminant host [54]. Therefore, as useful as could in vitro tests or mice models be to clarify pathogenicity mechanisms or to allow preliminary vaccine evaluations, they are unable to fully replace natural host experimental infections, which has to be chosen with special emphasis on the specie that represent the most relevant economical issue.

Broadly speaking, the results only indicated minor significant differences between the vaccinated/non-vaccinated groups although some quite obvious differences between the different serotype groups. One of the factors surely attributing to the non-significant differences is the fact the number of animals per group was low thus limiting the power of the statistical analysis. Further study focussing on some particular aspects using a higher number of individuals could clarify some of those points.
Amongst the BTV serotypes evaluated in this study, BTV1, BTV9 and BTV16 appeared to be better adapted to cattle host than BTV2 and BTV4. None of the tested serotypes could cause serious clinical disease. Viral RNA copy number was higher at viraemic peak in non-vaccinated animals. Viral detection at the viraemic peak and in the organs at necropsy suggests a partial and minor protection of BTV8 vaccination against infection with European heterologous serotypes in an experimental context. The very limited serological cross reactivity between the different tested serotypes most likely suggests cellular based mechanisms. It has been recently reported that West Nile virus lineages that induce different mortality rates in the field could cause similar mortality in experimental conditions, the discrepancy putatively thought to be linked to a different host competence among these strains [55]. Vector borne viruses are in permanent interaction with environment, hosts and vectors; therefore the epidemiological meaning of the potential effect of a mass anti-BTV8 vaccination to (partially) protect cattle livestock from heterologous serotypes remains uncertain.

\begin{abstract}
Abbreviations
BTV: bluetongue virus; BT: bluetongue disease; ELISA: enzyme linked immunosorbent assay; RTqPCR: reverse transcription quantitative polymerase chain reaction; BoHV1: bovine herpesvirus type 1; BSL3: biosafety level 3; TPI: The Pirbright Institute; CODA-CERVA: Centrum voor Onderzoek in Diergeneeskunde en Agrochemie-Centre d'étude et de recherches vétérinaires et agrochimiques; BHK: baby hamster kidney; DMEM: Dulbecco's modified eagle medium; $\mathrm{TCID}_{50}$ : tissue culture infectious dose 50; dpi: day post-infection; RNA: ribonucleic acid; VP7: viral protein 7; PN: percentage of negativity; SNT: seroneutralization; CDNA: complementary deoxyribonucleic acid; S2: segment 2; PFU: plaque forming unit; ANOVA: analysis of variance; NV and V: non-vaccinated and vaccinated; CPE: cytopathic effect; MLV: modified live vaccine; CTL: cytotoxic lymphocyte; VERO: verda reno.
\end{abstract}

\section{Competing interests}

The authors declare that they have no competing interests.

\section{Authors' contributions}

LM, FDP, CS and KdC designed the experimental protocol. CS and KdC allowed the coordination of the project. KdC and IDL provided the inocula. LM and WVC carried out experimental infections, cattle sampling and clinical followsup. LM and CS performed the necropsy. CT, LM and IDL carried out the laboratory analyses. CS and LM realized the statistical treatment of the data. LM, FDP, $\mathrm{CS}, \mathrm{KdC}$ and ET contributed to the manuscript drafting. All authors read and approved the final manuscript.

\section{Acknowledgements}

The authors are grateful to the members of staff at the Sciensano Machelen Experimental Centre (Belgium).

\footnotetext{
Author details

${ }^{1}$ Faculty of Veterinary Medicine, Research Unit in Epidemiology and Risk Analysis Applied to Veterinary Sciences (UREAR-ULg), Fundamental and Applied Research for Animal and Health (FARAH) Center, University of Liege, Liege, Belgium. ${ }^{2}$ Sciensano, Exotic Viruses and TSE, Ukkel, Belgium. ${ }^{3}$ Sciensano, Experimental Centre, Machelen, Belgium. ${ }^{4}$ Faculty of Veterinary Medicine, Fundamental and Applied Research for Animal and Health (FARAH) Center, Veterinary Virology and Animal Viral Diseases, University of Liege, Liege, Belgium.
} 


\section{Availability of data and materials}

The datasets used and/or analysed during the current study are available from the corresponding author on reasonable request.

\section{Ethics approval and consent to participate}

Experimental protocol has been approved by the ethical committee of the IPH-VAR (Institute of Public Health-Veterinary and Agrochemical Research, Groeselenberg 99, 1180 Uccle, nr. of the project 110228-01 RT 10/10 BLUETONGUE).

\section{Funding}

This research was funded by the Belgian Federal Public Service of Health, Food Chain Safety and Environment (contract RT 10/10 BLUETONGUE). None of the authors of this paper has a financial or personal relationship with other people or organizations that could inappropriately influence or bias the content of the paper. The funder has no role in study design, data collection and analysis, decision to publish or preparation of the manuscript.

\section{Publisher's Note}

Springer Nature remains neutral with regard to jurisdictional claims in published maps and institutional affiliations.

Received: 7 February 2018 Accepted: 25 June 2018

Published online: 16 July 2018

\section{References}

1. Maclachlan NJ, Drew CP, Darpel KE, Worwa G (2009) The pathology and pathogenesis of bluetongue. J Comp Pathol 141:1-16

2. Mertens P, Maan S, Samuel A, Attoui H (2005) Orbivirus, reoviridae. Virus taxonomy. In: Fauquet CM, Mayo MA, Maniloff J, Desselberger U, Ball LA (eds). VIIIth Report of the ICTV, London; 2005. Elsevier/Academic Press, New York. pp 466-483

3. Batten C, Darpel K, Henstock M, Fay P, Veronesi E, Gubbins S, Graves S, Frost L, Oura C (2014) Evidence for transmission of bluetongue virus serotype 26 through direct contact. PLoS One 9:e96049

4. Zientara S, Sanchez-Vizcaino JM (2013) Control of bluetongue in Europe. Vet Microbiol 165:33-37

5. Meiswinkel R, Baldet T, de Deken R, Takken W, Delecolle JC, Mellor PS (2008) The 2006 outbreak of bluetongue in northern Europe-the entomological perspective. Prev Vet Med 87:55-63

6. Wilson AJ, Mellor PS (2009) Bluetongue in Europe: past, present and future. Philos Trans R Soc Lond B Biol Sci 364:2669-2681

7. BLUETONGUE-EUROPE (02): FRANCE, BTV-8, BTV-1, resolved, oie. http:// www.promedmail.org/. Accessed 30 Jan 2014

8. BLUETONGUE_EUROPE (03): BELGIUM, BTV-8, resolved, oie. http://www. promedmail.org/. Accessed 29 Jan 2014

9. Coetzee P, Van Vuuren M, Stokstad M, Myrmel M, Venter EH (2012) Bluetongue virus genetic and phenotypic diversity: towards identifying the molecular determinants that influence virulence and transmission potential. Vet Microbiol 161:1-12

10. Kirkland PD, Hawkes RA (2004) A comparison of laboratory and "wild" strains of bluetongue virus - is there any difference and does it matter? Vet Ital 40:448-485

11. Erasmus BJ (1990) Bluetongue virus. In: Dinter Z, Morein B (eds) Virus infections of ruminants. Elsevier Biomedical Press, Amsterdam, pp 227-237

12. Jenckel M, Breard E, Schulz C, Sailleau C, Viarouge C, Hoffmann B, Hoper D, Beer M, Zientara S (2015) Complete coding genome sequence of putative novel bluetongue virus serotype 27. Genome Announc 3:e00016-15

13. Maan S, Maan NS, Belaganahalli MN, Potgieter AC, Kumar V, Batra K, Wright IM, Kirkland PD, Mertens PP (2016) Development and evaluation of real time RT-PCR assays for detection and typing of bluetongue virus. PLoS One 11:e0163014

14. Umeshappa CS, Singh KP, Pandey AB, Singh RP, Nanjundappa RH (2010) Cell-mediated immune response and cross-protective efficacy of binary ethylenimine-inactivated bluetongue virus serotype-1 vaccine in sheep. Vaccine 28:2522-2531
15. Hund A, Gollnick N, Sauter-Louis C, Neubauer-Juric A, Lahm H, Buttner M (2012) A two year BTV-8 vaccination follow up: molecular diagnostics and assessment of humoral and cellular immune reactions. Vet Microbiol 154:247-256

16. Breard E, Belbis G, Viarouge C, Nomikou K, Haegeman A, De Clercq K, Hudelet P, Hamers C, Moreau F, Lilin T, Durand B, Mertens P, Vitour D, Sailleau C, Zientara S (2015) Evaluation of adaptive immune responses and heterologous protection induced by inactivated bluetongue virus vaccines. Vaccine 33:512-518

17. The RNAs and proteins of dsRNA viruses. http://www.reoviridae.org/ dsRNA_virus_proteins/btv-collection.htm. Accessed 29 Jun 2015

18. Saegerman C, Mauroy A, Guyot H (2008) Bluetongue in ruminants: a standardised clinical report form for the use in different species. In: Saegerman C, Reviriego-Gordejo F, Pastoret PP (eds) Bluetongue in Northern Europe. OlE Publication, Paris, pp 82-87

19. Vandenbussche $F$, Vanbinst $T$, Verheyden B, Van Dessel W, Demeestere L Houdart P, Bertels G, Praet N, Berkvens D, Mintiens K, Goris N, De Clercq K (2008) Evaluation of antibody-ELISA and real-time RT-PCR for the diagnosis and profiling of bluetongue virus serotype 8 during the epidemic in Belgium in 2006. Vet Microbiol 129:15-27

20. Martinelle L, Dal Pozzo F, Sarradin P, De Leeuw I, De Clercq K, Thys C, Ziant D, Thiry E, Saegerman C (2011) Two alternative inocula to reproduce bluetongue virus serotype 8 disease in calves. Vaccine 29:3600-3609

21. Biteau-Coroller F, Gerbier G, Stark KD, Grillet C, Albina E, Zientara S, Roger $F$ (2006) Performance evaluation of a competitive ELISA test used for bluetongue antibody detection in France, a recently infected area. Vet Microbiol 118:57-66

22. Martinelle L, Dal Pozzo F, Sarradin P, De Leeuw I, De Clercq K, Thys C, Thiry E, Saegerman C (2013) Pulmonary artery haemorrhage in newborn calves following bluetongue virus serotype 8 experimental infections of pregnant heifers. Vet Microbiol 167:250-259

23. Dal Pozzo F, Martinelle L, Thys C, Sarradin P, De Leeuw I, Van Campe W, De Clercq K, Thiry E, Saegerman C (2013) Experimental co-infections of calves with bluetongue virus serotypes 1 and 8 . Vet Microbiol 165:167-172

24. Reed $\sqcup$, Muench $H$ (1938) A simple method of estimating fifty per cent endpoints. Am J Hyg 27:493-497

25. Dungu B, Gerdes T, Smit T (2004) The use of vaccination in the control of bluetongue in southern Africa. Vet Ital 40:616-622

26. Eschbaumer M, Schulz C, Wackerlin R, Gauly M, Beer M, Hoffmann B (2011) Limitations of sandwich ELISAs for bluetongue virus antibody detection. Vet Rec 168:643

27. Darpel KE, Batten CA, Veronesi E, Shaw AE, Anthony S, BachanekBankowska K, Kgosana L, Bin-Tarif A, Carpenter S, Muller-Doblies UU, Takamatsu HH, Mellor PS, Mertens PP, Oura CA (2007) Clinical signs and pathology shown by British sheep and cattle infected with bluetongue virus serotype 8 derived from the 2006 outbreak in northern Europe. Vet Rec 161:253-261

28. Eschbaumer M, Wackerlin R, Rudolf M, Keller M, Konig P, Zemke J, Hoffmann B, Beer M (2010) Infectious blood or culture-grown virus: a comparison of bluetongue virus challenge models. Vet Microbiol 146:150-154

29. Caporale M, Wash R, Pini A, Savini G, Franchi P, Golder M, Patterson-Kane J, Mertens P, Di Gialleonardo L, Armillotta G, Lelli R, Kellam P, Palmarini M (2011) Determinants of bluetongue virus virulence in murine models of disease. J Virol 85:11479-11489

30. Erra EO, Korhonen EM, Voutilainen L, Huhtamo E, Vapalahti O, Kantele A (2013) Dengue in travelers: kinetics of viremia and NS1 antigenemia and their associations with clinical parameters. PLoS One 8:e65900

31. Walz PH, Bell TG, Wells JL, Grooms DL, Kaiser L, Maes RK, Baker JC (2001) Relationship between degree of viremia and disease manifestation in calves with experimentally induced bovine viral diarrhea virus infection. Am J Vet Res 62:1095-1103

32. Tse H, To KK, Wen X, Chen H, Chan KH, Tsoi HW, Li IW, Yuen KY (2011) Clinical and virological factors associated with viremia in pandemic influenza A/H1N1/2009 virus infection. PLoS One 6:e22534

33. Barratt-Boyes SM, MacLachlan NJ (1995) Pathogenesis of bluetongue virus infection of cattle. J Am Vet Med Assoc 206:1322-1329

34. Eschbaumer M, Wackerlin R, Savini G, Zientara S, Sailleau C, Breard E, Beer M, Hoffmann B (2011) Contamination in bluetongue virus challenge experiments. Vaccine 29:4299-4301 
35. Caporale M, Di Gialleonorado L, Janowicz A, Wilkie G, Shaw A, Savini G, Van Rijn PA, Mertens P, Di Ventura M, Palmarini M (2014) Virus and host factors affecting the clinical outcome of bluetongue virus infection. J Virol 88:10399-10411

36. Samal SK, Livingston CW Jr, McConnell S, Ramig RF (1987) Analysis of mixed infection of sheep with bluetongue virus serotypes 10 and 17: evidence for genetic reassortment in the vertebrate host. J Virol 61:1086-1091

37. Modumo J, Venter EH (2012) Determination of the minimum protective dose for bluetongue virus serotype 2 and 8 vaccines in sheep. J S Afr Vet Assoc 83:17

38. Maan S, Maan NS, Samuel AR, O'Hara R, Meyer AJ, Rao S, Mertens PP (2004) Completion of the sequence analysis and comparisons of genome segment 2 (encoding outer capsid protein VP2) from representative isolates of the 24 bluetongue virus serotypes. Vet Ital 40:484-488

39. Andrew M, Whiteley P, Janardhana V, Lobato Z, Gould A, Coupar B (1995) Antigen specificity of the ovine cytotoxic $T$ lymphocyte response to bluetongue virus. Vet Immunol Immunopathol 47:311-322

40. Jones LD, Chuma T, Hails R, Williams T, Roy P (1996) The non-structural proteins of bluetongue virus are a dominant source of cytotoxic T cell peptide determinants. J Gen Virol 77:997-1003

41. Belbis G, Zientara S, Bahuon C, Sailleau C, Relmy A, Millemann Y, Breard E (2009) Approaches to DIVA ELISA for bluetongue diagnosis using bluetongue virus non-structural proteins. In: H. MRN (ed) European Buiatric Forum, Marseille, 1-3 December 2009. Saint-Pierre, Société Française de Buiatrie, p 40

42. Rojas JM, Rodriguez-Calvo T, Pena L, Sevilla N (2011) T cell responses to bluetongue virus are directed against multiple and identical CD4+ and CD8+ T cell epitopes from the VP7 core protein in mouse and sheep. Vaccine 29:6848-6857

43. Drew CP, Heller MC, Mayo C, Watson JL, Maclachlan NJ (2010) Bluetongue virus infection activates bovine monocyte-derived macrophages and pulmonary artery endothelial cells. Vet Immunol Immunopathol 136:292-296

44. DeMaula CD, Leutenegger CM, Bonneau KR, MacLachlan NJ (2002) The role of endothelial cell-derived inflammatory and vasoactive mediators in the pathogenesis of bluetongue. Virology 296:330-337

45. Venter GJ, Mellor PS, Wright I, Paweska JT (2007) Replication of liveattenuated vaccine strains of bluetongue virus in orally infected South African Culicoides species. Med Vet Entomol 21:239-247
46. Vazeille-Falcoz M, Mousson L, Rodhain F, Chungue E, Failloux AB (1999) Variation in oral susceptibility to dengue type 2 virus of populations of Aedes aegypti from the islands of Tahiti and Moorea, French Polynesia. Am J Trop Med Hyg 60:292-299

47. Vazeille M, Moutailler S, Coudrier D, Rousseaux C, Khun H, Huerre M, Thiria J, Dehecq JS, Fontenille D, Schuffenecker I, Despres P, Failloux AB (2007) Two Chikungunya isolates from the outbreak of La Reunion (Indian Ocean) exhibit different patterns of infection in the mosquito, Aedes albopictus. PLoS One 2:e1168

48. Savini G, MacLachlan NJ, Sanchez-Vizcaino JM, Zientara S (2008) Vaccines against bluetongue in Europe. Comp Immunol Microbiol Infect Dis 31:101-120

49. Monaco F, De Luca N, Morelli D, Pisciella M, Palmarini S, Di Giandomenico M, Savini G (2004) Field vaccination of cattle using a bivalent modifiedlive vaccine against bluetongue virus serotypes 2 and 9: effect on milk production. Vet Ital 40:661-663

50. Ferrari G, De Liberato C, Scavia G, Lorenzetti R, Zini M, Farina F, Magliano A, Cardeti G, Scholl F, Guidoni M, Scicluna MT, Amaddeo D, Scaramozzino P, Autorino GL (2005) Active circulation of bluetongue vaccine virus serotype-2 among unvaccinated cattle in central Italy. Prev Vet Med 68:103-113

51. Bonneau KR, DeMaula CD, Mullens BA, MacLachlan NJ (2002) Duration of viraemia infectious to Culicoides sonorensis in bluetongue virus-infected cattle and sheep. Vet Microbiol 88:115-125

52. Baylis M, O'Connell L, Mellor PS (2008) Rates of bluetongue virus transmission between Culicoides sonorensis and sheep. Med Vet Entomol 22:228-237

53. Carpenter S, Lunt HL, Arav D, Venter GJ, Mellor PS (2006) Oral susceptibility to bluetongue virus of Culicoides (Diptera: Ceratopogonidae) from the United Kingdom. J Med Entomol 43:73-78

54. Coetzee P, Van Vuuren M, Stokstad M, Myrmel M, van Gennip RG, van Rijn PA, Venter EH (2014) Viral replication kinetics and in vitro cytopathogenicity of parental and reassortant strains of bluetongue virus serotype 1, 6 and 8. Vet Microbiol 171:53-65

55. Del Amo J, Llorente F, Figuerola J, Soriguer RC, Moreno AM, Cordioli P, Weissenbock H, Jimenez-Clavero MA (2014) Experimental infection of house sparrows (Passer domesticus) with West Nile virus isolates of EuroMediterranean and North American origins. Vet Res 45:33
Ready to submit your research? Choose BMC and benefit from:

- fast, convenient online submission

- thorough peer review by experienced researchers in your field

- rapid publication on acceptance

- support for research data, including large and complex data types

- gold Open Access which fosters wider collaboration and increased citations

- maximum visibility for your research: over $100 \mathrm{M}$ website views per year

At $\mathrm{BMC}$, research is always in progress.

Learn more biomedcentral.com/submissions 